\begin{tabular}{|c|c|c|}
\hline BIODIK & $\begin{array}{c}\text { BIODIK: Jurnal IImiah Pendidikan Biologi } \\
\text { ISSN 2580-0922 (online), ISSN 2460-2612 (print) } \\
\text { Volume 6, Nomor 03, Tahun 2020, Hal. 392-401 } \\
\text { Available online at: } \\
\text { https://online-journal.unja.ac.id/biodik }\end{array}$ & BIODIK \\
\hline
\end{tabular}

Research Article OPEN ACCESS

\title{
Efektifitas Media Pembelajaran Berbasis Smartphone Untuk Mengembangkan Sikap Peduli Lingkungan Peserta Didik
}

\author{
(The Effectiveness of Smartphone Based Learning Media to Develop Attitudes Caring for \\ Students 'Environmental)
}

\author{
Calvin Talakua*, Centhya Victorin Maitimu
}

Program Studi Pendidikan Biologi, Jurusan MIPA, STKIP Gotong Royong Masohi

JIn. Transeram Belakang Negeri Haruru, Kota Masohi Kabupaten Maluku Tengah-Indonesia

${ }^{*}$ Corresponding Authors: talakua_calvin@yahoo.co.id

\begin{tabular}{|c|c|}
\hline Informasi Artikel & ABSTRACT \\
\hline $\begin{array}{l}\text { Submit: } 18-06-2020 \\
\text { Diterima: } 31-08-2020 \\
\text { Dipublikasikan: } 17-09-2020\end{array}$ & $\begin{array}{l}\text { This study aims to describe the effectiveness of using smartphone-based learning } \\
\text { media on ecosystem materials in developing students' environmental care attitudes. } \\
\text { The population of this study were students of class X SMA Negeri } 1 \text { Seram Utara } \\
\text { Barat even semester 2019/2020 academic year. The number of students was } 24 \\
\text { people. This research includes pre-experimental research using the One Group } \\
\text { Pretest-Posttest Design. Learning using smartphone-based media is carried out four } \\
\text { times face to face and one time giving the final test (posttest). The instrument used in } \\
\text { this study was a questionnaire for students' environmental care attitudes. The results } \\
\text { showed that the effectiveness of the use of smartphone learning media on ecosystem } \\
\text { material from the average value of the questionnaire for environmental care attitudes } \\
\text { of students reached } 80 \text { in the cultural category. The N-gain calculation is } 0.60 \text { in the } \\
\text { medium category. The Paired Sample T-test resulted in a significance level of } 0.00 \\
<0.05 \text { (effective). This shows that between the pre-test before using smartphone } \\
\text { learning media on ecosystem material and the post-test after using smartphone } \\
\text { learning media experiences a significant difference. Based on the results of several } \\
\text { tests it is concluded that smartphone learning media on ecosystem material is } \\
\text { effective in developing environmental care attitudes of SMA Negeri } 1 \text { students. North } \\
\text { West Seram. } \\
\text { Keywords: : Learning Media, Smartphone Media, Environmental Care Attitude }\end{array}$ \\
\hline Penerbit & ABSTRAK \\
\hline $\begin{array}{l}\text { Program Studi Pendidikan } \\
\text { Biologi, Fakultas Keguruan dan } \\
\text { IImu Pendidikan, Universitas } \\
\text { Jambi }\end{array}$ & $\begin{array}{l}\text { Penelitian ini bertujuan mendeskripsikan keefektifan dari penggunaan media } \\
\text { pembelajaran berbasis smartphone pada materi ekosistem dalam mengembangkan } \\
\text { sikap peduli lingkungan siswa. Populasi penelitian ini adalah peserta didik kelas X } \\
\text { SMA Negeri } 1 \text { Seram Utara Barat tahun ajaran } 2019 / 2020 \text { semester genap. Jumlah } \\
\text { peserta didik sebanyak } 24 \text { orang. Penelitian ini termasuk penelitian pra- } \\
\text { eksperimental menggunakan One Group Pretest-Posttest Design. Pembelajaran } \\
\text { menggunakan media berbasis smartphone dilaksanakan empat kali tatap muka dan } \\
\text { satu kali pemberian tes akhir (posttest). Instrumen yang digunakan dalam penelitian } \\
\text { ini adalah angket sikap peduli lingkungan siswa. Hasil penelitian menunjukkan bahwa } \\
\text { keefektifan penggunaan media pembelajaran smartphone pada materi ekosistem dari } \\
\text { nilai rata - rata angket sikap peduli lingkungan peserta didik mencapai } 80 \text { dengan } \\
\text { kategori membudaya. Perhitungan N-gain adalah 0,60 dengan kategori sedang. Uji } \\
\text { Paired Sample T-test memperoleh hasil tingkat signifikansi } 0,00<0,05 \text { (efektif). Hal } \\
\text { ini menunjukkan bahwa antara pre-test sebelum menggunakan media pembelajaran } \\
\text { smartphone pada materi ekosistem dan post-test setelah menggunakan media } \\
\text { pembelajaran smartphone mengalami perbedaan yang signifikan Berdasarkan hasil } \\
\text { beberapa uji disimpulkan bahwa media pembelajaran smartphonepada materi } \\
\text { eksosistem efektif dalam mengembangkan sikap peduli lingkungan siswa SMA } \\
\text { Negeri } 1 \text { Seram Utara Barat. }\end{array}$ \\
\hline
\end{tabular}




\section{PENDAHULUAN}

Proses belajar mengajar merupakan proses komunikasi interaktif antara guru dan siswa. Dalam proses komunikasi tersebut terkadang mengalami hambatan sehingga diperlukan perantara berupa media yang dapat menjembatani komunikasi antara guru dan siswa. Pada hakikatnya penggunaan media bertujuan untuk menciptakan pembelajaran yang lebih komunikatif dan bermakna bagi siswa ( Aripin, 2018). Dalam kurikulum 2013, guru tidak hanya sebagai pemeran utama yang menjadi pusat perhatian di kelas, karena pembelajaran dapat dilakukan dengan menggunakan berbagai sumber belajar termasuk penggunaan Informasi Teknologi (IT) yaitu fasilitas-fasilitas yang terdiri dari perangkat keras dan perangkat lunak dalam mendukung kualitas informasi yang diberikan kepada peserta didik secara cepat dan berkualitas.

Perkembangan teknologi perangkat mobile learning menjadi alternatif perangkat yang lebih murah dibandingkan personal Komputer seperti komputer dekstop atau laptop. Adanya perangkat yang murah dapat memudahkan siswa mengakses media pembelajaran. Salah satu jenis mobile learning adalah aplikasi android pada smartphone (Istiyanto, 2013). Berdasarkan hasil wawancara bersama guru Biologi SMA Negeri 1 Seram Utara Barat, guru mengemukakan bahwa media pembelajaran yang digunakan hanyalah torso,buku cetak, LKS dan slide power point. Aplikasi android pada smartphone belum pernah digunakan dalam proses pembelajaran sehingga media pembelajaran yang dapat membantu peserta didik lebih mudah memahami materi biologi sangatlah dibutuhkan. Penggunaan smartphone dikalangan peserta didik didominasi untuk games, youtube, dan jejaring sosial seperti facebook, line, Instagram dan twitter.

Media pembelajaran yang berbasiskan perangkat mobile mempunyai beberapa keunggulan. Keunggulan dari perangkat mobile antara lain mudah dibawa, dapat terhubung ke jaringan kapan saja dan di mana saja, lebih fleksibel dalam mengakses sumber belajar, kedekatan komunikasi, peserta didik dapat terlibat dan aktif. Kemudahan dan harga yang murah menjadi keunggulan utama. Kemudahan dalam membuat aplikasi edukatif juga telah mendapat dukungan dari beberapa pihak.

Media pembelajaran yang akan digunakan merupakan sebuah aplikasi android yang akan menampilkan materi pembelajaran. Materi pembelajaran yang ditampilkan pada aplikasi android ini adalah materi ekosistem. Melalui pengetahuan dan pengalaman yang diperoleh dalam proses pembelajaran ini peserta ddik memiliki pengetahuan yang baik terhadap ekosistem dan dapat diaplikasikan dalam 
kehidupan sehari-hari melalui sikap mereka. Salah satu sikap yang dapat dikembangkan adalah sikap peduli lingkungan.

Sikap peduli lingkungan yang dimiliki peserta didik sebagai hasil dari proses belajar, dapat meningkatkan kepedulian peserta didik akan kelestarian daya dukung dari alam lingkungannya ( Gunawan, 2019). Melalui media pembelajaran aplikasi android ini peserta didik diberikan contoh-contoh yang dapat mengubah pola pikir peserta didik tentang lingkungan disekitarnya. Media pembelajaran ini memberikan wahana yang strategis dalam upaya menumbuhkembangkan sikap peduli lingkungan, dengan demikian dapat menangulangi masalah lingkungan melalui perubahan sikap mendasar peserta didik terhadap lingkungannya (Munawaroh, 2017).

Goleman (2012) merumuskan indikator mengenai kesadaran lingkungan diantaranya yaitu, mengembangkan empati terhadap segala bentuk kehidupan (developing empathy for all forms of life), mempraktikan keberlangsungan hidup sebagai tindakan kelompok mayarakat (embracing sustainability as a community practice), membuat sesuatu yang tidak terlihat menjadi terlihat (making the invisible visibel), mengantisipasi dampak tidak terduga (anticipating unintended consequences), dan memahami bagaimana kehidupan alam berlangsung (understanding how nature sustains life). Tujuan penelitian ini adalah untuk mengetahui efektifitas media pembelajaran Mobile Learning berbasis Smartphone dalam mengembangkan sikap peduli lingkungan peserta didik.

\section{METODE PENELITIAN}

Jenis penelitian yang digunakan dalam penelitian ini adalah penelitian kuantitatif pra-eksperimental dengan menggunakan one group pretestposttest design (Sugiyono, 2017). Desain yang akan digunakan dalam penelitian ini dapat dilihat pada tabel 1.

Tabel 1. Desain penelitian one group pretest-posttest design

\begin{tabular}{ccc}
\hline Pre-test & Treatment & Post-test \\
\hline $\mathrm{O}_{1}$ & $\mathrm{X}$ & $\mathrm{O}_{2}$ \\
\hline
\end{tabular}

Penelitian ini dilakukan di SMA Negeri 1 Seram Utara Barat pada semester genap tahun ajaran 2019/2020. Pembelajaran menggunakan media pembelajaran berbasis smartphone dilaksanakan dalam empat kali tatap muka dan satu kali pemberian tes akhir (post-test).

Populasi penelitian ini adalah peserta didik kelas X SMA Negeri 1 Seram Utara Barat tahun ajaran 2019/2020 semester genap. Jumlah sample yang dipilih sebanyak 25 orang pada kelas $\mathrm{X}_{2}$. Teknik pengambilan sampel yaitu purposive sampling yaitu penentuan sampel dengan pertimbangan tertentu. Pengambilan sampel juga sesuai dengan pertimbangan guru biologi yang mengajar di sekolah tersebut. Media pembelajaran berbasis smartphone ini berisikan materi ekosistem, di 
mana angket sikap peduli lingkungan disusun sesuai dengan sikap peduli lingkungan.

Teknik pengumpulan data yang digunakan pada penelitian ini adalah teknik non tes menggunakan angket sikap peduli lingkungan yang terdiri atas 20 item pernyataan. Teknik non tes digunakan untuk mengukur sikap peduli lingkungan peserta didik melalui penggunaan media pembelajaran berbasis smartphone. Analisis data yang dilakukan dalam penelitian ini antara lain analisis deskriptif dan analisis inferensial meliputi uji $\mathrm{N}$-gain, uji normalitas, uji homogenitas, dan uji T-test (Paired Samples T-test).

\section{HASIL DAN PEMBAHASAN}

Pada penelitian ini, tes sikap peduli lingkungan peserta didik dilakukan sebanyak 2 kali, masing-masing sebelum pembelajaran (pretes), dan sesudah pembelajaran (postes). Tes yang dilakukan menggunakan angket sikap peduli lingkungan peserta didik. Pengelompokan skor sikap peduli lingkungan peserta didik diadopsi dari Kemendikbud (2010b). Berdasarkan pada pedoman tersebut, rata-rata skor hasil sikap peduli lingkungan 20-40 dikategorikan belum terlihat, 41-60 kategori mulai terlihat, 61-80 kategori mulai berkembang, 81-100 kategori membudaya.

Deskripsi data nilai sikap peduli lingkungan peserta didik pretest dan postest dari lima variabel sikap peduli lingkungan yang digunakan akan disajikan pada tabel 2 dan untuk mempermudah dalam menginterpretasikan data maka disajikan pula dalam bentuk diagram batang seperti yang ditunjukan pada gambar 1. Berdasarkan hasil perhitungan sikap peduli lingkungan peserta didik pada tabel 2, rata-rata pengelompokan skor sikap peduli lingkungan peserta didik pada kelas yang diajarkan menggunakan media pembelajaran berbasis smartphone sebelum dan sesudah pembelajaran tetap dalam kategori mulai berkembang dan berdasarkan profil skor sikap peduli lingkungan peserta didik pada kelas yang diajarkan menggunakan media smartphone terjadi peningkatan setelah pembelajaran.

\begin{tabular}{|c|c|c|c|c|c|}
\hline No & $\begin{array}{l}\text { Kriteria Sikap Peduli } \\
\text { Lingkungan }\end{array}$ & Pre-test & Kategori & Pre-test & Kategori \\
\hline 1 & $\begin{array}{l}\text { Developing empathy for all forms of } \\
\text { life }\end{array}$ & 60,67 & $\begin{array}{l}\text { Mulai } \\
\text { terlihat }\end{array}$ & 75,22 & $\begin{array}{c}\text { Mulai } \\
\text { Berkembang }\end{array}$ \\
\hline 2 & $\begin{array}{l}\text { Embracing sustainability as a } \\
\text { community practice }\end{array}$ & 70,34 & $\begin{array}{l}\text { Mulai } \\
\text { terlihat }\end{array}$ & 78,68 & $\begin{array}{l}\text { Mulai } \\
\text { Berkembang }\end{array}$ \\
\hline 3 & Making the invisible visibel & 65,85 & $\begin{array}{l}\text { Mulai } \\
\text { terlihat }\end{array}$ & 80 & $\begin{array}{l}\text { Mulai } \\
\text { Berkembang }\end{array}$ \\
\hline 4 & $\begin{array}{c}\text { Anticipating unintended } \\
\text { consequences }\end{array}$ & 62,8 & $\begin{array}{l}\text { Mulai } \\
\text { terlihat }\end{array}$ & 74,5 & $\begin{array}{c}\text { Mulai } \\
\text { Berkembang }\end{array}$ \\
\hline 5 & Understanding how nature sustains lif & 68,25 & $\begin{array}{l}\text { Mulai } \\
\text { terlihat }\end{array}$ & 70,25 & $\begin{array}{c}\text { Mulai } \\
\text { Berkembang }\end{array}$ \\
\hline
\end{tabular}




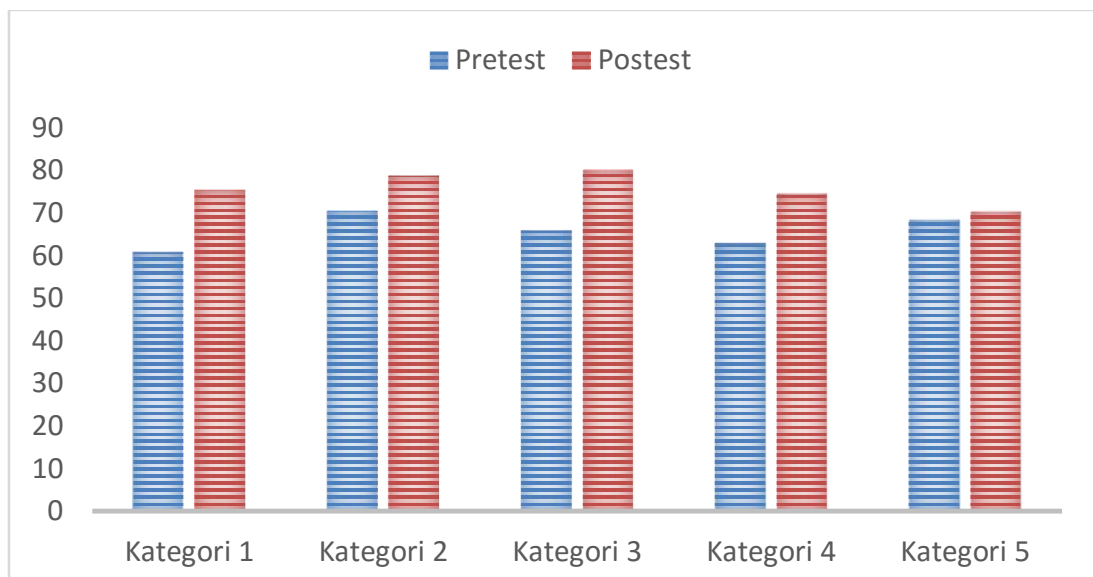

Gambar 1. Profil sikap peduli lingkungan peserta didik SMA Negeri 1 Seram Utara Barat.

Berdasarkan tabel 2 hasil pre-test dan post-test sikap peduli lingkungan peserta didik mengalami peningkatan. Hal tersebut ditandai adanya perubahan nilai rata - rata yang signifikan. Kedua adalah menghitung $\mathrm{N}$-gain dari pretest-posttest setiap peserta didik dan diperoleh hasil dengan beberapa kriteria yaitu rendah, sedang, dan tinggi sesuai dengan tabel 3 .

Tabel 3. Kriteria N-gain nilai pret-test dan post-test

\begin{tabular}{ccc}
\hline Data & Rata -rata $\mathbf{N}$-gain & Kategori \\
\hline $\begin{array}{c}\text { Nilai pre-test dan } \\
\text { post-test }\end{array}$ & 0,60 & Sedang \\
\hline
\end{tabular}

Tabel 3 menampilkan hasil dari rata-rata $\mathrm{N}$-gain yaitu sebesar 0,60. Hal ini menyatakan bahwa efektifitas media pembelajaran media smartphone yang dikembangkan termasuk dalam kategori sedang. Selanjutnya dilakukan uji normalitas Kolmogorov Smirnov. Data yang digunakan untuk uji normalitas Kolmogorov Smirnov adalah rata - rata nilai pretest, posttest dan $\mathrm{N}$-gain Hasil uji dapat dilihat pada Tabel 4.

Tabel 4. Uji Normalitas Kolmogorov Smirnov pretest, posttest, dan N-gain

\begin{tabular}{ccc}
\hline No & Jenis Data & Sig $^{*}$ \\
\hline 1 & Pre-test & 0,858 \\
\hline 2 & Post-test & 0,902 \\
\hline 3 & N-gain & 0,950 \\
${ }^{*}=$ signifikansi level 0,05 &
\end{tabular}

Berdasarkan hasil uji pada tabel 4 beberapa data seperti pre-test dan posttest berdistribusi normal. Keempat, melakukan uji homogenitas menggunakan Lavene test untuk mengatahui apakah data yang diperoleh homegen atau tidak. Hasil Lavene test dapat dilihat pada tabel 5. 
Tabel 5. Uji homogenitas pre-test dan post-test

\begin{tabular}{cccc}
\hline Jenis Data & $\begin{array}{c}\text { Jenis Uji } \\
\text { Homogenitas }\end{array}$ & Sig $^{*}$ & Ket \\
\hline Hasil pre-test dan post-test & Lavene Test & 0,70 & Homogen \\
\hline
\end{tabular}

Berdasarkan Tabel 5 hasil uji homogenitas dengan Lavene test hasil pretest dan posttest dapat dinyatakan data homogen. Kelima, melakukan uji Paired Sample T-Test. Uji Paired Sample T-Test dilakukan dengan tujuan untuk melihat keefektifan penggunaan media pembelajaran berbasis smartphone apakah apakah mampu mengembangkan sikap peduli lingkungan siswa SMA Negeri 1 Seram Utara Barat. Selain itu uji Paired Sample T-Test juga akan menunjukkan perbedaan nyata sebelum dan sesudah menerapkan media pembelajaran berbasis smartphone pada materi ekosistem. Hasil uji Paired Sample T-Test dapat dilihat pada tabel 6.

Tabel 6. Uji paired sample t-test pretest dan post-test

\begin{tabular}{cccc}
\hline Uraian & Std. Dev & $\mathbf{t}$ & Sig $^{\boldsymbol{*}}$ \\
\hline Pre-test dan post-tes & 10,71743 & 1.858 & 0,000 \\
\hline
\end{tabular}

Berdasarkan tabel 6 bahwa $\mathrm{H}_{0}$ ditolak maka $\mathrm{H}_{1}$ diterima, karena sig.0,000<0,05. Hal ini menunjukkan bahwa antara pre-test sebelum menggunakan media pembelajaran berbasis smartphone dan post-test setelah menggunakan media pembelajaran berbasis smartphone mengalami perbedaan yang signifikan Dari beberapa hasil yang diperoleh bahwa media pembelajaran berbasis smartphone dalam mengembangkan sikap peduli lingkungan peserta didik SMA Negeri 1 Seram Utara Barat teruji keefektifan dengan katagori sedang. Sesuai dengan kategori yang telah ditentukan sebelumnya maka media pembelajaran berbasis smartphone dapat digunakan sebagai media ajar dengan materi ekosistem.

Hasil penelitian menujukan bahwa media pembelajaran berbasis smartphone dalam mengembangkan sikap peduli lingkungan peserta didik teruji keefektifan dengan katagori sedang. Sesuai dengan kategori yang telah ditentukan sebelumnya maka media pembelajaran berbasis smartphone dapat digunakan sebagai media ajar dengan materi ekosistem.

Hasil tersebut disebabkan Mobile Learning berbasis Smartphone mempermudah interaksi antara peserta didik dengan bahan/materi pelajaran. Peserta didik dapat saling berbagi informasi atau pendapat mengenai berbagai hal yang menyangkut pelajaran atau kebutuhan pengembangan diri peserta didik. Selain itu, guru dapat menempatkan bahan-bahan belajar dan tugas-tugas yang harus dikerjakan oleh peserta didik di tempat tertentu di dalam web untuk di akses oleh peserta didik. Sesuai dengan kebutuhan, guru dapat pula memberikan kesempatan kepada peserta didik untuk mengakses bahan belajar tertentu maupun soal-soal ujian yang hanya dapat diakses oleh peserta didik sekali saja dan dalam rentangan waktu tertentu pula.

Salah satu media pembelajaran yang diharapkan dapat menciptakan suasana belajar yang menarik dan kondusif yaitu dengan penggunaan media Mobile Learning 
berbasis Smartphone. Menggunakan media pembelajaran tersebut diharapkan dapat memberikan pembaharuan dalam proses pembelajaran di kelas. Media Mobile Learning berbasis Smartphone ini melengkapi buku elektronik yang sudah ada, sehingga mampu mengakomodasi semua kegiatan pembelajaran interaktif seperti mendengarkan, membaca, menulis dan juga permainan, adapun kelemahannya yaitu membutuhkan jumlah Perangkat Smartphone yang sesuai dengan jumlah peserta didik. Pemilihan media Mobile Learning berbasis Smartphone dirasa cocok dengan pengembangan Kurikulum saat ini.

Prasetyo (2015) yang menjelaskan bahwa pembelajaran Mobile Learning berbasis Smartphone berfungsi sebagai suplemen, apabila peserta didik mempunyai kebebasan memilih, apakah akan memanfaatkan materi pembelajaran elektronik atau tidak. Dalam hal ini, tidak ada kewajiban/keharusan bagi peserta didik untuk mengakses materi pembelajaran elektronik. Sekalipun sifatnya opsional, siswa yang memanfaatkannya tentu akan memiliki tambahan pengetahuan atau wawasan sehingga mampu meningkatkan sikap peduli lingkungan siswa.

Media pembelajaran Mobile Learning berbasis Smartphone dapat memberdayakan sikap peduli lingkungan peserta didik. Hal ini dikarenakan nilai rata-rata sikap peduli lingkungan peserta didik masih rendah hanya berada pada kategori mulai terlihat sebelum menggunakan media pembelajaran Mobile Learning berbasis Smartphone. Setelah menggunakan media pembelajaran Mobile Learning berbasis Smartphone sikap peduli lingkungan peserta didik meningkat menjadi kategori mulai berkembang.

Pengembangan media pembelajaran Mobile Learning berbasis Smartphone dalam memberdayakan sikap peduli lingkungan mendapat respon yang sangat baik oleh peserta didik. Selanjutnya menurut Rusman (2013) melalui pembelajaran Mobile Learning berbasis Smartphone minat belajar dapat ditingkatkan karena pembelajaran Mobile Learning berbasis Smartphone berfungsi sebagai komplemen berarti materi e-learning diprogramkan untuk menjadi materi enrichment (pengayaan) atau remedial bagi peserta didik di dalam mengikuti kegiatan pembelajaran konvensional. Tujuannya agar semakin memantapkan tingkat penguasaan peserta didik terhadap materi pelajaran yang disajikan guru di kelas. Sebagai remedial, apabila peserta didik mengalami kesulitan dalam memahami materi petajaran yang disampaikan guru secara tatap muka di kelas. Tujuannya agar peserta didik semakin lebih mudah memahami materi pelajaran yang disajikan guru di kelas.

Penggunaan media pembelajaran Mobile Learning berbasis Smartphone ini membuat siswa tertarik belajar. Minat siswa tersebut ditunjukan dengan seseorang memperhatikan hal yang diamati secra terus menerus dan hal itu menimbulka. Hal tersebut menyebabkan siswa memahami dengan jelas bagaimana lingkungan dan bagaimana sikap untuk menjaga dan peduli terhadap lingkungan yang ada disekitarnya. 


\section{UCAPAN TERIMA KASIH}

Penulis memberikan ucapan terima kasih/pengakuan/acknowledgments kepada pihak yang berkontribusi atas keterlaksanaan penelitian ini. Ucapan terimakasih ini diberikan kepada:

1. Kalsum Sehulawano, S.Pd.I., M.Pd selaku Ketua STKIP Gotong Royong Masohi yang telah memberi motivasi dan dorongan dalam penelitian ini.

2. Kepala Sekolah SMA Negeri 1 Seram Utara Barat yang telah membantu dan berkontribusi dalam pelaksanaan penelitian ini.

3. Marlen Sahureka, S.Si., M.Sc selaku Ketua LPPM yang telah berkontribusi dalam membantu pelaksanaan penelitian ini.

\section{KESIMPULAN}

Berdasarkan analisis data dan hasil pembahasan dapat disimpulkan dalam beberapa hal. Pertama, hasil analisis respon siswa dapat diperoleh untuk seluruh kategori sikap peduli lingkungan peserta didik mencapai kategori mulai berkembang. Peserta didik memberikan respon positif terhadap pengunaan media pembelajaran berbasis smartphone. Sehingga media pembelajaran smartphone materi ekosistem telah efektif dan dapat digunakan dalam proses pembelajaran. Kedua, hasil antara pretest sebelum menggunakan media pembelajaran smartphone dan post-test setelah menggunakan media pembelajaran smartphone mengalami perbedaan yang signifikan. Meskipun tes berpikir kreatif peserta didik termasuk dalam kategori sedang dalam uji $\mathrm{N}$-gain, media pembelajaran smartphone memiliki kelebihan yaitu mampu mengembangkan sikap peduli lingkungan peserta didik SMA Negeri 1 Seram Utara Barat. Berdasarkan hasil pengamatan dan penelitian yang telah dilakukan maka saran yang dapat diajukan adalah guru Biologi SMA di Kecamatan Seram Utara Barat melakukan menerapkan pembelajaran Mobile Learning berbasis Smartphone sebagai alternatif pembelajaran di kelas sehingga siswa tidak mudah bosan dan termotivasi untuk mengikuti pelajaran. Bagi peneliti lanjut, hasil penelitian pembelajaran berbasis smartphone diharapkan dapat dijadikan landasan untuk penelitian selanjutnya untuk materi lain, sehingga dapat dijadikan sebagai bahan pertimbangan guru bidang studi untuk menerapkan media pembelajaran dikelas.

\section{DAFTAR PUSTAKA}

Alfi, A. F. (2001). Dasar Sistem Kendali (Bahan Ajar. Jurusan Pendidikan Teknik Elektro Fakultas Teknik UNY.

Ally, M. (2009). Mobile learning: transforming the delivery of education and training. AU Press.

Andini Dwi Rachmawati Baiduri, M. M. E. (2020). Efektivitas Media Pembelajaran Interaktif Berbantuan Web Dalam Mengembangkan Kemampuan Berpikir Kreatif. AKSIOMA: Jurnal Program Studi Pendidikan Matematika, 9(3), 540550. 
Arif Budi Utomo, Upik Yelianti, Muswita, E. J. W. (2018). Pengembangan E-Book

Berbasis Mobile Learning Pada Mata Kuliah Struktur Tumbuhan. BIOEDUKASI: Jurnal Pendidikan Biologi, 11(2), 93-104.

Arifin, Z. (2012). Penelitian Pendidikan Metode dan Paradigma Baru. Rusda.

Chandrasegaran, A. L., Treagust, D. F. dan Mocerino, M. (2008). An Evaluation of a Teaching Intervention to Promote Students' Ability to Use Multiple Levels of Representation When Describing and Explaining Chemical Reaction"s. Research in Science Education, 38(2), 237-248.

Goleman D., Bennet L., B. (2012). Eco Literate, How Educators Are Cultivating Emotional, Social and Ecological Intellegence. Jossey-Bass.

Hadi Gunawan, G. (2019). Analisis sikap peduli lingkungan siswa sd negeri 184 pekanbar. Jurnal pendidikan guru sekolah dasar, 8(2).

Hake, R. . (2004). Design-Based Research: A Primer for Physics Education Researchers. The American Journal of Physics, 2(1).

Hayatun Munawaroh. (2017). Pengembangan Media Pembelajaran Berbasis Kvisoft Pada Materi Ekosistem Untuk Memberdayakan Sikap Peduli Lingkungan peserta Didik Kelas X SMA. Universitas Islam Negeri Raden Intan Lampung.

Hirsh-Pasek, K., Zosh, J.M., Golinkoff, R.M., Gray, J.H., Robb,M.B., dan Kaufman, J. (2015). Putting Education in "Educational" apps: Lessons From teh Science of Learning. Psychological Science in the Public Interest, 16(1), 3-34.

Istiyanto, J. E. (2013). Pemrograman Smartphone Menggunakan SDK Android dan Hacking Android. Graha llmu.

Ipin, A. (2018). Konsep dan Aplikasi Mobile Learning dalam Pembelajaran Biologi. Jurnal Bio Educatio, 3(2), 01-09.

Ismawati, R., Saptorini, dan Wijayati, N. (2013). Pengaruh Model Pembelajaran Inkuiri Berstrategi React Terhadap Hasil Belajar Kimia Siswa SMA Kelas XI. Jurnal Inovasi Pendidikan Kimia, 7(1), 1044-1050.

Kim, D., Rueckert, D., Kim, D.J., dan Seo, D. (2013). Students' preceptions and experiences of mobile learning. Language Learning Dan Technology, 17(3), 5273.

Nurrokmah, I.E. dan Sunarto, W. (2013). Pengaruh Penerapan Virtual Lab Berbasis Inkuiri Terhadap Hasil Belajar Siswa. Chemistry in Education, 2(1), 201-208.

Prasetyo, Y.D., Yektyastuti, R., Solihah, M., Ikhsan, J. dan Sugiyarto, K. . (2015). Pengaruh penggunaan media pembelajaran kimia berbasis aplikasi android terhadap peningkatan motivasi siswa SMA. Seminar Nasional Pendidikan Sains $\checkmark$.

Rochmani, S. (2011). Penggunaan Media Gambar Untuk Meningkatkan Prestasi Belajar Bahasa Mandarin Siswa Kelas V Di SD Tripusaka Surakarta.

Slameto. (2010). Belajar dan Faktor-Faktor yang Mempengaruhinya. Rineka Cipta. Wasti, S. (2013). Hubungan Minat Belajar Dengan Hasil Belajar Mata Pelajaran Tata Busana Di Madrasah Aliyah 2 Padang. Universitas Negeri Padang. 
Valk, J.H., Rashid, A.T., dan Elder, L. (2010). Using Mobile Phones to Improve Educational Outcomes:An Analysis of Evidence from Asia. International Review of Research in Open and Distance Learning, 11(1), 117-140.

Zamroni, M. (2009). Perkembangan Teknologi Komunikasi dan Dampaknya terhadap Kehidupan. Jurnal Dakwah, 10(2), 202. 